Review

\title{
Diet-Induced Dysbiosis of the Intestinal Microbiota and the Effects on Immunity and Disease
}

\author{
Kirsty Brown $^{\dagger}$, Daniella DeCoffe ${ }^{\dagger}$, Erin Molcan and Deanna L. Gibson * \\ Department of Biology, University of British Columbia Okanagan, Kelowna, BC V1V 1V7, Canada; \\ E-Mails: kirsty.brown12@gmail.com (K.B.); ubcpeermentor.daniella@gmail.com (D.D.); \\ erinmolcan@gmail.com (E.M.)
}

$\dagger$ These authors contributed equally to this work.

* Author to whom correspondence should be addressed; E-Mail: deanna.gibson@ubc.ca; Tel.: +1-250-807-8790; Fax: +1-250-807-8005.

Received: 30 June 2012; in revised form: 9 August 2012 / Accepted: 15 August 2012 /

Published: 21 August 2012

\begin{abstract}
The gastrointestinal (GI) microbiota is the collection of microbes which reside in the GI tract and represents the largest source of non-self antigens in the human body. The GI tract functions as a major immunological organ as it must maintain tolerance to commensal and dietary antigens while remaining responsive to pathogenic stimuli. If this balance is disrupted, inappropriate inflammatory processes can result, leading to host cell damage and/or autoimmunity. Evidence suggests that the composition of the intestinal microbiota can influence susceptibility to chronic disease of the intestinal tract including ulcerative colitis, Crohn's disease, celiac disease and irritable bowel syndrome, as well as more systemic diseases such as obesity, type 1 diabetes and type 2 diabetes. Interestingly, a considerable shift in diet has coincided with increased incidence of many of these inflammatory diseases. It was originally believed that the composition of the intestinal microbiota was relatively stable from early childhood; however, recent evidence suggests that diet can cause dysbiosis, an alteration in the composition of the microbiota, which could lead to aberrant immune responses. The role of the microbiota and the potential for diet-induced dysbiosis in inflammatory conditions of the GI tract and systemic diseases will be discussed.
\end{abstract}

Keywords: intestinal microbiota; inflammation; disease susceptibility; nutrition 


\section{Introduction}

\subsection{Intestinal Microbiota}

The intestinal microbiota is the collection of microbes that reside in the gastrointestinal (GI) tract and is comprised of over 1000 different species that contributes 3.3 million unique microbial genes in the GI tract of humans [1,2]. This intricate microbial system includes bacteria which live in a symbiotic relationship with their host and some microbes which have potentially pathogenic characteristics. The mammalian microbiota is highly variable at lower taxonomic levels, however there are four dominant phyla: Firmicutes, Bacteroidetes, Actinobacteria and Proteobacteria [3]. Firmicutes and Bacteroidetes account for $>90 \%$ of the bacterial population in the colon [4] while Actinobacteria and Proteobacteria (which includes Enterobacteriaceae) are regularly present but are scarce $(<1 \%-5 \%)$ [1].

Microbes in the GI tract are essential for host digestion including the breakdown of complex carbohydrates including dietary fibers, production of short chain fatty acids and synthesis of vitamins (reviewed in [5]). As a result, the composition of the microbiota has the ability to influence host metabolic functions. The microbiota of the GI tract is also critical in determining the host's susceptibility to GI infections [6]. It can protect the host from pathogenic bacteria directly by preventing their attachment via colonization resistance, as well as outcompeting the pathogens for nutrients, and maintaining appropriate intestinal $\mathrm{pH}$ [7]. A recent report has shown that an individual's microbiota, regardless of age, nationality, gender, and body-mass index, falls into one of three main 'enterotypes' which differ in their phylogenetic composition and functional characteristics [8]. This is the first report to suggest that the human microbiota clusters into functional groups which may respond differently to diet or medications, and may represent the future direction of functional microbiota characterization.

Colonization of the GI tract begins during the birthing process as the newborn is exposed to maternal and environmental microbes [9]. The infant microbiota is marked by heterogeneity and instability until approximately 2-4 years of age, [10,11] when it becomes more stable, resembling an adult microbiota [12]. Initial colonization of the intestine does not appear to be random [13] but instead, pre-programmed. This was initially shown by Rawls et al. (2006) who performed reciprocal microbiota transplants in zebrafish and mice, which have similar microbiota at the division level, but different composition at the species level [14]. When the zebra fish microbiota was transplanted into germ-free (GF) mice and vice versa, the host developed a bacterial community similar to its own species, revealing that genetics pre-programs the ecology of our GI tracts [14]. However, there is growing evidence that the microbial ecology can be influenced by several epigenetic factors including mode of infant delivery [15], antibiotic exposure [16], neonatal nutrition [17], adult nutrition [18], stress [19,20], age [21] and degree of hygiene [22], as well as stochastic events including bacterial infection [23]. For example, infants born vaginally acquire the mother's vaginal and intestinal flora including Bacteroides, Bifidobacterium, Lactobacillus, and Escherichia coli, while those born via caesarean section have increased levels of skin-associated bacteria including Staphylococcus spp. [24] which persists into childhood [25]. Therefore, while host genetics can predict microbial composition to an extent, several extrinsic factors contribute to the development of an individual's unique microbial fingerprint and as a result, susceptibility to several diseases. 


\subsection{Intestinal Microbiota and the Immune System}

The intestinal microbiota plays a crucial role in the development of local and systemic immunity, as well as in maintaining colonic homeostasis [26-28]. The importance of the intestinal microbiota in immune system development is highlighted by GF studies which reveal that intestinal structure and function are impaired [29] through decreased IgA secretion [30], decreased number and function of intraepithelial lymphocytes [31], and reduced lymphatic tissue [32]. The microbiota has been shown to drive the expansion of B and T cells in Peyer's patches and mesenteric lymph nodes, especially CD4+ $\mathrm{T}$ cells, including FOXp3-expressing $\mathrm{T}$ regulatory $\left(\mathrm{T}_{\text {reg }}\right)$ cells [33]. Specifically, Bifidobacteria spp. enhance the maturation of the mucosal sIgA system, while early colonization with Bacteroides fragilis down-regulates lipopolysaccharide (LPS) responsiveness in infancy [34]. Beyond the postnatal period and into adulthood, the microbiota is necessary to induce regulatory mechanisms intended to keep both mucosal and systemic immunity in balance so that while we are tolerant of harmless bacteria we are still able to form adequate responses to pathogens. Many species of bacteria have been shown to have specific effects on the host. For example, segmented filamentous bacteria, which adhere closely to the intestinal epithelium [35], have been shown to induce Th17 responses [36] and increase the number of $\mathrm{T}_{\text {reg }}$ cells in both the small intestine and colon [37]. Polysaccharide A associated with $B$. fragilis is proposed to activate CD4 $+\mathrm{T}$ helper cells and promote $\mathrm{Th} 1 / \mathrm{Th} 2$ balance [38]. Mono-colonization with $B$. fragilis promotes $\mathrm{T}_{\text {reg }}$ cells and induces anti-inflammatory cytokine IL-10 production, which results in protection from chemically induced colitis [39]. Another key group of microbes are Clostridium coccoides and C. leptum (clusters IV and V respectively), which protect against inflammatory bowel disease (IBD) [40]. Additionally, mono-colonization with Clostridia (46 species from clusters IV and V) in GF mice strongly promotes IL-10 producing $\mathrm{T}_{\text {reg }}$ cells [41]. While $\mathrm{T}_{\text {reg }}$ cells play a critical role in this regulation, other factors like short-chain fatty acid production by microbes help regulate other important processes like intestinal homeostasis. Clostridium coccoides are major producers of short chain fatty acids, particularly butyrate, which is an energy source for colonocytes and has been shown to protect against damaging inflammatory responses [42]. Other short chain fatty acids, such as propionic acid, are beneficial at low concentrations but have neurotoxic effects in high quantities and may play a role in the development and persistence of the symptoms of autism [43]. Given the vital relationship between the microbiota and the function of the intestine, it is crucial that the microbiota functions normally to maintain balanced immunity and homeostasis. An altered microbiota, termed dysbiosis, could lead to altered immune functions and increased risk of disease. Thus, intestinal colonization by the microbiota between infancy through the next four years of life may represent a critical control point during which immune tolerance and disease susceptibility develop as a result of responses to enteric bacteria. Understanding how extrinsic factors such as diet alter disease susceptibility through changes in the microbiota could provide insight into the function of microbes in healthy and diseased individuals.

\subsection{Diet-Induced Dysbiosis of the Intestinal Microbiota}

The influence of diet on the composition of the microbiota has been shown during the initial colonization phase: breast fed infants have higher levels of Bifidobacteria spp. while formula fed 
infants have higher levels of Bacteroides spp., as well as increased Clostridium coccoides and Lactobacillus spp. [44]. Beyond the postnatal period, the microbiota was suspected to be relatively stable throughout life. However, several recent studies have shown that dietary factors alter the microbial community resulting in biological changes to the host (Table 1). In fact, the composition of the gut microbiota strongly correlates with diet as demonstrated by a study assessing the relative contributions of host genetics and diet in shaping the gut microbiota and modulating metabolic syndrome phenotypes in mice. In mice fed a diet high in fat, there are many key gut population changes, such as the absence of gut barrier-protecting Bifidobacteria spp. Overall, dietary changes could explain $57 \%$ of the total structural variation in gut microbiota whereas changes in genetics accounted for no more than $12 \%$ [45]. This indicates that diet has a dominating role in shaping gut microbiota and changing key populations may transform healthy gut microbiota into a disease-inducing entity. For example, the "Western" diet, which is high in sugar and fat, causes dysbiosis which affects both host GI tract metabolism and immune homeostasis [46]. This was modeled in a humanized mouse model where adult human fecal microbiota was transplanted into GF mice. The mice were fed a low-fat, plant polysaccharide-rich diet and when switched to a "Western" diet, the microbiota composition shifted to an overgrowth of Firmicutes including Clostridium innocuum, Eubacterium dolichum, Catenibacterium mitsuokai and Enterococcus spp., as well as a significant reduction in several Bacteroides spp. [18]. In mice, carbohydrate-reduced diets result in enriched populations of bacteria from the Bacteroidetes phyla, [47] and calorie-restricted diets prevent the growth of Clostridium coccoides, Lactobacillus spp. and Bifidobacteria spp., which are all major butyrate producers required for colonocyte homeostasis [48]. Diets rich in complex carbohydrates show less pathogenic species such as Mycobacterium avium subspecies paratuberculosis and Enterobacteriaceae [49] than diets higher in fat or protein [48,50-52]. Complex carbohydrates also increase levels of beneficial Bifidobacteria spp. such as B. longum subspecies longum, B. breve and B. thetaiotaomicron [53]. Refined sugars, on the other hand, mediate the overgrowth of opportunistic bacteria like $C$. difficile [54] and $C$. perfringens by increasing bile output [55]. Vegetarianism alters intestinal microbiota in humans because high amounts of fiber result in increased short chain fatty acid production by microbes which decrease the intestinal $\mathrm{pH}$. This prevents the growth of potentially pathogenic bacteria such as E. coli and other members of Enterobacteriaceae [56]. Interestingly, it has been found that European children have a microbiota depleted of Bacteroidetes and enriched in Enterobacteriaceae compared to rural African children which the authors attributed to low dietary fiber intake by Europeans [57]. While not yet demonstrated in humans, it has been suggested that maternal diet can influence the microbiota of the offspring. A high-fat diet (44\% condensed milk and $8 \%$ corn oil) fed to rats and transferred to their suckling pups via breast milk caused specific microbial alterations in their pup's microbiota fingerprint, such as enriched populations of Lactobacillus spp. and Enterococcus spp. and depleted Bacteroides spp. and Prevotella spp. [58]. Other studies conducted in mice have found that high-fat diets rich in safflower oil, an omega-6 polyunsaturated fatty acid (PUFA), reduces the abundance of Bacteroidetes while enriching the populations of Firmicutes, Actinobacteria and Proteobacteria [59,60]. The authors showed that the consumption of safflower oil stimulated the growth of $\delta$-Proteobacteria by enhancing bacterial genes for chemotaxis and flagella development, giving them a competitive advantage over other bacterial groups that colonize the GI tract [61]. However, another study showed that a diet rich in saturated (milk) fat and not safflower oil triggered the growth of $\delta$-Proteobacteria, 
specifically Bilophila wadsworthia, in the cecum [62]. These conflicting observations could be a result of the region of the GI tract investigated since the cecum and colon are different in both microbial inhabitance and function. Thus a conclusion regarding the benefits of safflower oil over milk fat cannot be made from these two studies alone.

Table 1. Summary of diet-induced dysbiosis.

\begin{tabular}{|c|c|c|c|}
\hline Diet & Bacteria Altered & Effect on Bacteria & References \\
\hline High-fat & Bifidobacteria spp. & Decreased (absent) & {$[45]$} \\
\hline \multirow[t]{2}{*}{$\begin{array}{l}\text { High-fat and } \\
\text { high-sugar }\end{array}$} & $\begin{array}{l}\text { Clostridium innocuum, } \\
\text { Catenibacterium mitsuokai } \\
\text { and Enterococcus spp. }\end{array}$ & Increased & {$[18]$} \\
\hline & Bacteroides spp. & Decreased & {$[18]$} \\
\hline Carbohydrate-reduced & Bacteroidetes & Increased & [49] \\
\hline Calorie-restricted & $\begin{array}{c}\text { Clostridium coccoides, } \\
\text { Lactobacillus spp. and } \\
\text { Bifidobacteria } \text { spp. }\end{array}$ & Decreased (growth prevented) & {$[48]$} \\
\hline \multirow[t]{2}{*}{ Complex carbohydrates } & $\begin{array}{c}\text { Mycobacterium avium } \\
\text { subspecies paratuberculosis } \\
\text { and } \text { Enterobacteriaceae }\end{array}$ & Decreased & [49] \\
\hline & $\begin{array}{l}\text { B. longum subspecies longum, } \\
\text { B.breve and B. thetaiotaomicron }\end{array}$ & Increased & {$[53]$} \\
\hline Refined sugars & C. difficile and C. perfringens & Increased & {$[54,55]$} \\
\hline Vegetarian & E. coli & Decreased & {$[56]$} \\
\hline \multirow[t]{3}{*}{$\begin{array}{c}\text { High } n-6 \text { PUFA from } \\
\text { safflower oil }\end{array}$} & Bacteroidetes & Decreased & {$[59,60]$} \\
\hline & $\begin{array}{l}\text { Firmicutes, Actinobacteria } \\
\text { and Proteobacteria }\end{array}$ & Increased & {$[59,60]$} \\
\hline & $\delta$-Proteobacteria & Increased & [61] \\
\hline Animal milk fat & 8-Proteobacteria & Increased & [62] \\
\hline
\end{tabular}

Microbial changes in the GI tract have profound effects on host inflammatory and metabolic responses. For example, protein-rich diets increase the activity of bacterial enzymes such as $\beta$-glucuronidase, azoreductase and nitroreductase, which produce toxic metabolites that trigger inflammatory responses [63]. Because of the intricate balance that exists within the microbiota, alterations in one group or species may not only affect the host directly, but can also disrupt the entire microbial community. For example, members from the phyla Firmicutes, Actinobacteria, Verrucomicrobium and Bacteroidetes can degrade complex carbohydrates not absorbed by the host [64] and can also inhibit the growth of opportunistic pathogens such as Clostridium spp. and members of Enterobacteriaceae like E. coli $[65,66]$. Dysbiosis can also alter the metabolic activity of other members of the microbiota in the gut [67]. Thus, it is conceivable that some diets promote the growth of microbes that could have detrimental effects on their host while other dietary factors could promote beneficial microbes. It is unknown whether diet-induced dysbiosis is a transient or long-term event. If dysbiosis is a long-term event, then postnatal nutrition could be used to promote changes in the microbiota early in life during the development of a more stable microbiota. In support of this, 
consumption of formula supplemented with fish oil has the capacity to alter the microbial composition in the infant; however, it is unknown if these microbial changes would be long lasting or transient [68]. Although this study did not identify the specific microbes that changed, nor did it examine the effect on intestinal immunity, it does suggest that the microbiota could be modified through dietary factors to enrich beneficial microbes and prevent diseases associated with dysbiosis.

\section{Intestinal Microbiota and Disease}

The natural homeostasis of gut microbial communities change during many disease pathologies including: obesity, metabolic syndrome, diabetes, inflammatory bowel disease (IBD), irritable bowel syndrome (IBS) and celiac disease. In many cases, there is evidence implicating various dietary factors in the onset of these diseases which will be discussed below. Both the microbiota and the intestinal mucosa are exposed to dietary antigens and as discussed here, recent evidence has shown that certain dietary choices can cause dysbiosis. However, little is known about the effects of nutrition on inducing specific microbial populations that are either protective and prevent specific diseases, or conversely, are damaging and cause disease. This is an important area of research since dietary choices modify the ecology of the intestinal microbiota which could affect an individual's susceptibility to many inflammatory diseases. While there is evidence that specific dietary factors are linked directly to host responses invovled in disease risk, it is also plausible that such an effect, at least in part, is due to shifts in the gut microbiota ecology (Figure 1).

Figure 1. Diet-induced dysbiosis affects disease susceptibility. The intestinal microbiome (microbial ecology and their genetic material) is influenced by both host genetics and the environment including dietary factors. In diseases including IBD, diabetes and obesity, diet is implicated as a contributing factor by having direct effects on host metabolism and/or immune responses. However, recent evidence suggests that diet also influences the composition of the microbiome. This could, in turn, affect host immunity and metabolism and alter susceptibility to disease.

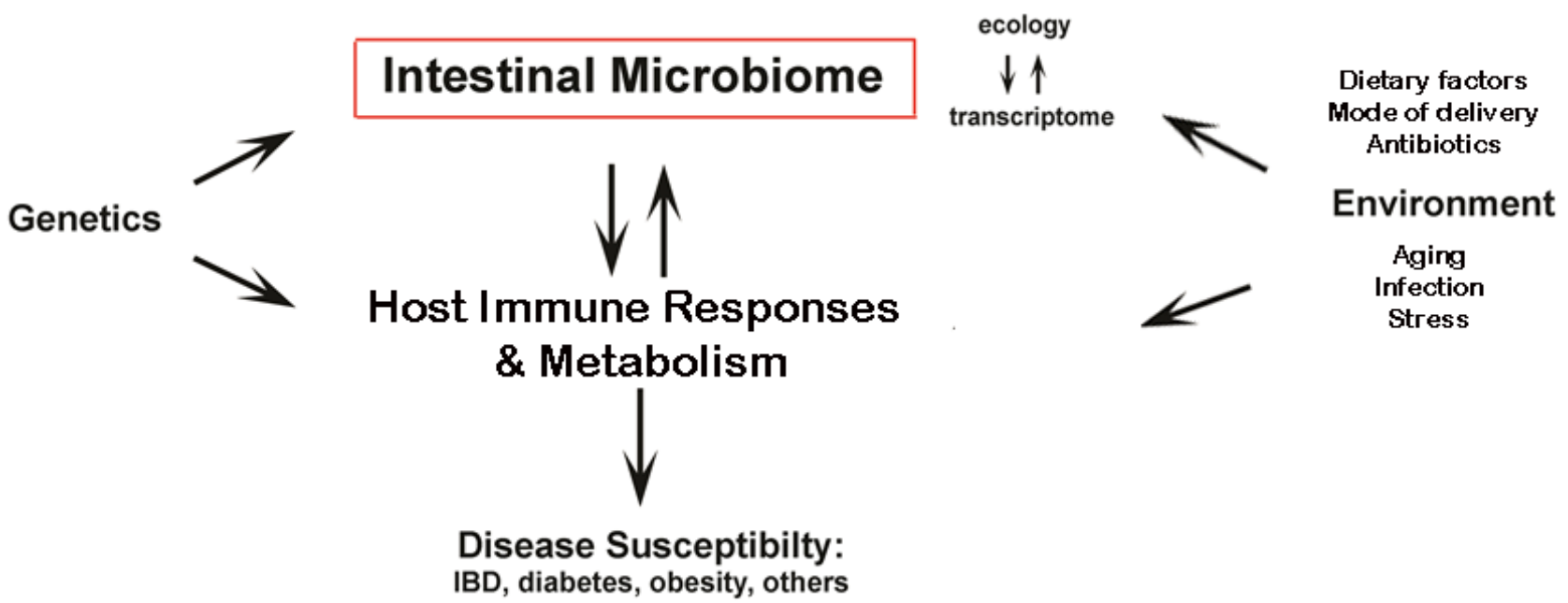




\subsection{Obesity, Metabolic Syndrome and Type 2 Diabetes}

The gut microbiota participates in the body's metabolism by affecting energy balance, glucose metabolism, and low-grade inflammation associated with obesity and related metabolic disorders. Obesity is associated with dysbiosis in the intestinal tract of both men and mice. As previously discussed, diet can influence dysbiosis and host metabolism [18]. In fact, the obese microbiome shows an increased ability to harvest energy from the diet [69], a feature that is transmissible between obese and non-obese mice despite similar energy intake [70]. Firmicutes and Bacteroidetes represent the two largest phyla in the human and mouse microbiota and a shift in the ratio of these phyla has been associated with many disease conditions, including obesity. In obese humans, there is decreased abundance of Bacteroidetes compared to lean individuals [70,71] and weight loss in obese individuals results in an increase in the abundance of Bacteroidetes [72]. However, there is conflicting evidence on the composition of the obese microbiota phenotype with regards to Bacteroidetes and Firmicutes ratios [73,74]. Obese/overweight children also display increased Enterobacteriaceae compared to children of the same age group (4-5 years) with a normal body-mass index [75]. As well, Bifidobacteria spp. from the phyla Actinobacteria, has been shown to be depleted in both obese mice and human subjects [76,77]. While it is not yet clear which specific microbes are inducing or preventing obesity, evidence suggests that the microbiota is a factor. In support of this, GF mice do not develop obesity [72,78], yet an obese microbiota induces obesity in GF mice [59]. Additionally, vancomyocin-treated high-fat fed mice gain less weight than vancomycin-treated mice fed a control diet despite similar caloric intake [79]. This shows that targeted manipulation of the microbiota results in divergent metabolic outcomes depending on the composition of the diet. The microbiota has been linked to insulin resistance or type 2 diabetes (T2D) via metabolic syndrome and indeed the microbiota of individuals with T2D is also characterized by an increased Bacteroidetes/Firmicutes ratio, as well as an increase in Bacillus and Lactobacillus spp. [80]. It was also observed that the ratio of Bacteriodes-Prevotella to C. coccoides-E. rectale positively correlated with glucose levels but did not correlate with body mass index [80]. This suggests that the microbiota may influence T2D in conjunction with or independently of obesity.

Obesity, metabolic syndrome and T2D are also associated with systemic low-grade inflammation. One mechanism that may explain microbial-induced obesity associated with metabolic syndrome and $\mathrm{T} 2 \mathrm{D}$, is endotoxemia which is characterized by excess circulating LPS which triggers systemic inflammation $[81,82]$. Mice injected with LPS show increased weight gain and insulin resistance along with macrophage accumulation in white adipose tissue [83]. In humans, high-fat Western-style diets fed to individuals over one month can induce a $71 \%$ increase in plasma levels of endotoxins, suggesting that endotoxemia may develop in individuals with GI barrier dyfunction connected to dysbiosis [82]. Furthermore, T2D patients have increased levels of plasma LPS [84] and mice fed a high-fat diet have an increase in LPS-containing bacteria which contribute to systemic inflammation, leading to metabolic syndrome and insulin resistance [81]. A recent study which aimed to clarify the mechanism between LPS levels and glucose metabolism found that although LPS increases macrophage infiltration essential for systemic inflammation preceding insulin resistance, LPS alone does not impair glucose metabolism [83]. This indicates that other factors may be involved in the progression to insulin resistance. For example, regulation of the gut innate immunity may influence the 
development of metabolic syndrome and obesity [85]. Mice lacking toll-like receptor (TLR)5, a transmembrane protein expressed in the intestinal mucosa that binds bacterial flagella, develop metabolic syndrome associated with dysbiosis and low-grade inflammation which was worsened following a high-fat diet [86]. Further studies are required to elucidate the microbial factors involved and their influence in the regulation of obesity, metabolic syndrome and T2D.

Alterations in the microbiota may affect host immune system balance and lead to increased translocation of bacterial antigens towards metabolically active tissues. This would result in a chronic inflammatory state and impaired metabolic functions such as insulin resistance, hepatic fat deposition, insulin unresponsiveness and excessive adipose tissue development. This imbalance could occur at the onset of metabolic disease. Therefore, early treatment of dysbiosis may slow down or prevent the epidemic of metabolic diseases and hence the corresponding lethal cardiovascular consequences [87]. Probiotic and prebiotic treatments may be an approach to reversing host metabolic alterations associated with dysbiosis observed in obesity [88]. Prebiotic fibers may benefit obesity by normalizing dysbiosis that occurs in the gut. Using genetically obese rats, one group found that dosing with prebiotic fibers increased Firmicutes and decreased Bacteroidetes, which is the microbial profile found in lean phenotypes, along with an increase in Bifidobacteria spp. and Lactobacillus spp. [89]. The administration of Lactobacillus spp. as a probiotic in one study produced variable results with respect to weight gain in humans, suggesting that different species of Lactobacilli have different effects on weight change that are host-specific [74]. Restoring the microbiota may attenuate the metabolic conditions associated with obesity and help individuals maintain a healthy weight [90].

\subsection{Type 1 Diabetes}

The GI microbiota was first considered as a factor contributing to Type 1 diabetes (T1D) when it was observed that penetrance of diabetes in non-obese diabetic (NOD) mice was dependent on the animal facility that the mice were housed in [91]. Since then, mouse and rat models of T1D have been shown to have microbiota marked by decreased diversity and decreased Lactobacillus spp., as well as a decrease in the Firmicutes/Bacteroidetes ratio [92,93]. Most recently, a clinical study has shown that genetically susceptible infants who develop T1D also have lower microbial diversity than those who do not develop the disease [94]. How these specific changes in microbial populations translate into the development of T1D is unknown, but one belief is that certain microbial antigens promote $\mathrm{T}$ cells involved in $\beta$-cell destruction. It is possible that this process is accelerated through a dysfunctional intestinal barrier which has long been associated both clinical and experimentally with T1D [95-98]. Alterations in innate immune signaling may also be playing a critical role since GF NOD mice lacking the innate adaptor protein myeloid differentiation primary response gene (MyD)88 develop robust diabetes, while specific pathogen free mice do not and colonization of GF mice with specific pathogen free microbiota attenuates diabetes [93]. This suggests that microbial antigens through the innate immune system are involved in T1D progression. Specifically, segmented filamentous bacterium, a non-cultivatable and strict anaerobe, promotes Th17 cell differentiation and positively correlates with protection from T1D in NOD mice [99]. The microbiota appears to be essential in maintaining the Th17/ $\mathrm{T}_{\text {reg }}$ cell balance in intestinal tissues, mesenteric and pancreatic lymph nodes, and in developing insulitis, although progression to overt diabetes has not been shown to be controlled by the 
microbiota [100]. This suggests that although the microbiota is essential in directing inflammatory responses leading to insulitis, progression to diabetes involves other mechanisms.

There is evidence that dietary and microbial antigens independently influence T1D, however the potential for diet-induced dysbiosis leading to T1D is not well defined. Oral ingestion of probiotics and prebiotics represent ways to induce change in the microbiota and have shown potential in altering diabetes onset: Lactobacillus johnsonii N6.2 protects BB-rats from T1D by mediating intestinal barrier function and inflammation [101,102] and a combination probiotic VSL\#3 has been shown to attenuate insulitis and diabetes in NOD mice [103]. Prebiotics are less studied, but there is evidence that breast feeding protects human infants against T1D [104]. Breast milk contains many complex oligosaccharides [105] which are prebiotic as they promote the growth of beneficial bacterial groups [106]. Certain food antigens are associated with advanced $\beta$-cell destruction in T1D in humans (cow's milk, fruit juices, eggs and soft drinks) [107,108] and many diets have been shown to protect against T1D in rodent models (low protein, high-fat, low omega-6:omega-3 PUFA ratio, soy-based and lactose free) [109-112]. This indicates that altering the microbiota through probiotics and prebiotics can influence disease progression and that dietary intervention also influences diabetes onset. Understanding diet-induced dysbiosis may be a promising angle to promote a microbiota which helps prevent autoimmune diseases like T1D.

\subsection{Inflammatory Bowel Disease}

The etiology of IBD, inclusive of Crohn's disease and ulcerative colitis, is multifactorial, often seen in genetically susceptible individuals with impaired intestinal mucosal integrity. As a result, microbial antigens more readily cross the epithelial barrier and activate immune cells which cause inappropriate and potentially chronic inflammation. The microbiota is critical for maintaining intestinal homeostasis through activation of innate immune TLRs [113] and could also play a causal role in the impaired mucosal integrity and repair seen in IBD patients. In fact, dysbiotic microbiota can induce murine colitis [114], and is observed in IBD patients by the reduction in microbial diversity [115,116], the enrichment of bacteria from the family Enterobacteriaceae [117-119] and the depletion in bacteria from the phyla Bacteroidetes and certain Firmicutes [40]. The mechanisms by which dysbiosis contributes to IBD are not well defined, but the increase in invasive bacterial species coupled with a decrease in protective bacteria could result in inappropriate immune cell activation and subsequent disruption of the Th1 and Th17 immune responses, increased mucosal permeability, and loss of immunological tolerance. Our group has recently shown that the intestinal microbiota protects against susceptibility to lethal infectious colitis by regulating protective inflammatory and redox responses [6]. The intestinal microbiota is considered to be a major factor in the pathogenesis of IBD and as a result there is great interest in identifying which populations of microbes promote protective responses in the gut.

Emerging evidence has also identified dietary lipid intake as an important factor contributing to the etiology of IBD [120-125]. At least one study, in a Danish population, found that excessive consumption of omega-6 PUFA increases ulcerative colitis risk by $30 \%$; whereas consumption of docosahexaenoic acid, an omega-3 PUFA, reduced the disease burden by 77\% [122]. Indeed, fish oil tablets are promoted as a "cure" for diseases like IBD [124] but their effects on GI health are 
conflicting with some studies showing a beneficial result $[120,122,123]$ and other studies revealing they actually exacerbate colitis [126,127]. While it is conceivable that excessive omega-6 PUFA consumption is linked to increased IBD risk, the assumption made is that dietary fatty acids directly alter the host's intestinal immune responses. While this is likely, it is also plausible that such an effect, at least in part, is due to shifts in the ecology of the gut microbiota. Both the microbiota and the intestinal mucosa are exposed to dietary antigens, suggesting the possibility that IBD susceptibility could be influenced by diet through the type of microbes that are influenced by nutritional factors. Along this line of thinking, we have shown that a microbiota enriched with Bacteroidetes promotes host intestinal immune and redox responses that protect mice from lethal infectious colitis [6]. This demonstrates that the microbiota is driving host responses and alters disease susceptibility. However, little is known about the effects of nutrition on inducing specific microbial populations that are either protective and prevent IBD, or conversely, are damaging and cause IBD. This is an important area of research since understanding how dietary choices modify the ecology of the intestinal microbiota could affect an individual's susceptibility to IBD, as well as directing further development and clinical usage of specific probiotic treatments. However, thus far clinical trials with probiotics have produced variable results against IBD [128], potentially since it is not known if they colonize the intestine long-term. Thus, identifying methods that promote and maintain beneficial microbes which are already present in the intestine to help balance the immune system and maintain GI health is a potential preventative measure or treatment against IBD.

\subsection{Irritable Bowel Syndrome}

IBS accounts for up to $40 \%$ of outpatient visits to a gastroenterologist [129]. Although the pathogenesis is poorly understood, there is evidence that the microbiota may be involved. The fecal microbiota of individuals with IBS differs greatly from that of healthy individuals [130]. Healthy individuals appear to have a more diverse gut microbial community than individuals who suffer from IBS [131]. Small intestinal bacterial overgrowth is also observed in a subset of IBS cases [132]. The microbiota of IBS patients compared with controls has a 2-fold increase in the ratio of Firmicutes to Bacteroidetes [133,134]. Patients with IBS have increased levels of Clostridia spp. [133] and decreased levels of Bifidobacteria spp. compared to controls [133,135,136]. One study also found that fecal samples from IBS patients have higher diversity of Bacteroidetes and Lactobacillus spp. [137]. In contrast, another group observed no differences between Bacteroides spp., Bifidobacteria spp., Lactobacillus spp., and Enterococcus spp. between IBS patients and controls [138]. There are two general classifications of IBS, diarrheoa-predominant and constipation-predominant, each of which seems to be associated with specific alterations in microbiota. Diarrhoea-predominant IBS is associated with significant increases in detrimental bacteria like Proteobacteria $[139,140]$, decreases in beneficial bacteria such as Lactobacillus spp. [135,141], Actinobacteria and Bacteroidetes [142], as well as an overall reduction in microbial diversity [143]. Constipation-predominant IBS patients have increased amounts of Firmicutes [135] and decreased levels of lactate-producing and utilizing bacteria like Eubacterium hallii and Anaerostipes caccae [144]. How the microbiota contributes to IBS is not known, but one factor may be low-grade mucosal inflammation, which could be initiated by the 
microbiota. In support of this, IBS patients have increased expression of TLR4 and 5 which initiate innate immune responses through microbial stimuli [145].

In a cohort of active IBS patients, 52\% attributed their symptoms to dietary components: $34 \%$ believe that vegetables evoke the uncomfortable symptoms of IBS, $29 \%$ relate their symptoms to fruits, $15 \%$ to milk, $15 \%$ to fat consumption, $6 \%$ to peppers and spices, and $4 \%$ to sugar [146]. Another study identified carbohydrate-rich foods, coffee, alcohol and hot spices as the cause of symptomatic expression in IBS patients [147]. Recently, research has focused on probiotics and prebiotics as therapeutics for IBS. Probiotics have been shown to modulate the mucosal immune system and improve intestinal barrier function, validating their potential as therapeutics for gastrointestinal-associated diseases [148]. The therapeutic effects of probiotics are associated with the stabilization of intestinal microbiota [149]. Bifidobacteria spp. has been shown to effectively alleviate IBS and significantly improve IBS symptoms like pain/discomfort, distension/bloating, urgency and digestive disorder $[150,151]$. Although there is currently no treatment for IBS, therapy with probiotics is beginning to emerge as a potential method of treatment.

\subsection{Celiac Disease and Other Food Allergies}

Celiac disease is a chronic inflammatory enteropathy caused by an autoimmune response to gluten peptides derived from bread wheat, barley, and rye which are taken up and presented by macrophages, which are then recognized by CD4+ T-cells. This triggers the release of pro-inflammatory cytokines that damage the small intestinal mucosae [152,153]. Although the mechanism of celiac disease progression is well defined, there is recent evidence that suggests the microbiota plays an important role in the pathophysiology of the disease. Breast-feeding [154] as well as vaginal delivery [155] have been shown to protect from this disorder potentially by promoting a healthy microbiota during initial colonization. Predisposed infants have gut microbiota lacking Bacteroidetes and a high abundance of Firmicutes [156]. Many groups have found that celiac patients have different fecal microbiota from that of healthy adults characterized by increased Bifidobacteria spp. [156-159], Lactobacillus spp. [157,158,160], Bacteroides spp., Staphylococcus spp. [154,158,161] and E. coli [160,161]. Conversely, some groups have found that Bifidobacteria spp. were lower in celiac patients compared to controls [154,161]. Also, Bifidobacteria spp. are less diverse in celiac children [162] and one group found that B. longum attenuates the production of inflammatory cytokines and the CD4+ T-cell mediated immune response in an animal model of gliadin-induced enteropathy [163]. Overall, higher incidence of Gram-negative and potentially pro-inflammatory bacteria are present in the microbiota of celiac children which is linked to the symptoms associated with the disease by favoring the pathological progress of the disorder [164]. Altered gene expression of TLR2 and 9, as well as, an inhibitory adaptor protein Toll interacting protein or TOLLIP in small intestinal biopsies in celiac disease suggests that microbiota-associated factors may be important in the development of the disease [165].

A gluten-free diet is currently the only treatment for celiac disease, and it has been shown that the bacterial composition is altered in treated and untreated adults with celiac disease [166]. A gluten-free diet decreases the abundance of Firmicutes and increases the number of Proteobacteria. In celiac individuals this results in reduced immune responses, contradictory to the belief that Proteobacteria are 
initiators of immune responses [160]. However, a gluten-free diet may not completely restore the natural balance of the microbiota normally seen in healthy individuals in those patients that have experienced dysbiosis due to gluten sensitivity [158]. Administration of Lactobacillus casei has been found to be effective in restoring normal mucosal architecture and gut-associated lymphoid tissue homeostasis in a mouse model of gliadin-induced enteropathy [167]. This suggests that specific microbes may be involved in promoting certain immunological responses in susceptible individuals, and may be a potential target for reducing the enteropathy associated with the disease.

Dysbiosis could create aberrant immune responses leading to other food allergies. The intestinal microbiota is important for the development of oral tolerance which prevents the immune system from reacting to harmless commensal bacterial and food antigens [168]. Common food allergies, such as those to milk, egg and nut products may be related to dysbiosis of the intestinal microbiota. In support of this, one group found that stimulation of intestinal immunocytes by Lactobacillus spp. may regulate excessive antigen-specific cytokine responses [169]. Infants (less than 12 months old) with sensitivity to formula have unusually low levels of Bifidobacteria spp. and Lactobacillus spp. and high levels of Clostridia spp., Staphylococcus spp. and E. coli [170]. As well, Firmicutes (specifically Lactobacillus spp.) and Bifidobacteria spp. have been shown to decrease, and levels of Enterobacteriaceae are increased [171] in individuals with food allergies. The addition of lactose to the diet modulates the composition of gut microbiota by increasing the total fecal counts of Lactobacillus spp. and Bifidobacteria spp., while decreasing levels of Bacteroides spp. [172].

Probiotics have been suggested as a therapy for food allergy. One group found that supplementation with Bifidobacterium appears to modify the gut microbiota in a manner that may alleviate allergic inflammation by decreasing the numbers of $E$. coli while protecting against increases in Bacteroidetes during weaning [171]. Another study showed that probiotic bacteria induced in vivo increased plasma levels of anti-inflammatory IL-10 and total IgA in children with allergic predisposition [173]. Although this may represent treatment options for individuals with food allergies, further studies are needed to confirm these conclusions.

\section{Conclusions}

The intestinal microbiota has essential functions in host metabolism and in directing immune system development. Dysbiosis is observed in many inflammatory diseases of the GI tract and in those which are linked to the GI tract either metabolically or immunologically. It is still not clear if dysbiosis contributes to the pathogenesis and symptoms of these diseases or is simply a consequence of these diseases. While there has been a focus on how diet correlates with the increased incidence of many inflammatory-driven diseases, an altered microbiota resulting from diet-induced dysbiosis may also be a factor that contributes to the inappropriate inflammatory responses that occur during these diseases. Probiotics and prebiotics may have the potential to be effective therapeutics to alleviate the symptoms associated with inflammatory diseases; however, the long-term effects are unknown. As our understanding of the microbiota continues to grow, promoting microbes which can prevent or control inflammatory-mediated diseases through diet may represent an exciting therapeutic avenue. 


\section{Acknowledgments}

K. B. and D. D. were funded by the Canadian Association of Gastroenterology (CAG) summer-student award and E. M. was funded by an I. K. Barber School of Arts \& Sciences Undergraduate Research Award. D. L. G. is funded through grants from the Bill and Melinda Gates Foundation, Crohn's and Colitis Foundation of Canada, Natural Sciences and Engineering Research Council and the Intestinal Diseases Education Awareness Society.

\section{Conflict of Interest}

The authors declare no conflict of interest.

\section{References}

1. $\quad$ Eckburg, P.B.; Bik, E.M.; Bernstein, C.N.; Purdom, E.; Dethlefsen, L.; Sargent, M.; Gill, S.R.; Nelson, K.E.; Relman, D.A. Diversity of the human intestinal microbial flora. Science 2005, 308, 1635-1638.

2. Proctor, L.M. The human microbiome project in 2011 and beyond. Cell Host Microbe 2011, 10, 287-291.

3. Dethlefsen, L.; McFall-Ngai, M.; Relman, D.A. An ecological and evolutionary perspective on human-microbe mutualism and disease. Nature 2007, 449, 811-818.

4. Ley, R.E.; Hamady, M.; Lozupone, C.; Turnbaugh, P.J.; Ramey, R.R.; Bircher, J.S.; Schlegel, M.L.; Tucker, T.A.; Schrenzel, M.D.; Knight, R.; et al. Evolution of mammals and their gut microbes. Science 2008, 320, 1647-1651.

5. Tappenden, K.A.; Deutsch, A.S. The physiological relevance of the intestinal microbiotaContributions to human health. J. Am. Coll. Nutr. 2007, 26, 679S-683S.

6. Ghosh, S.; Dai, C.; Brown, K.; Rajendiran, E.; Makarenko, S.; Baker, J.; Ma, C.; Halder, S.; Montero, M.; Ionescu, V.A.; et al. Colonic microbiota alters host susceptibility to infectious colitis by modulating inflammation, redox status, and ion transporter gene expression. Am. J. Physiol. Gastrointest. Liver Physiol. 2011, 301, G39-G49.

7. Stecher, B.; Hardt, W.D. Mechanisms controlling pathogen colonization of the gut. Curr. Opin. Microbiol. 2011, 14, 82-91.

8. Arumugam, M.; Raes, J.; Pelletier, E.; Le Paslier, D.; Yamada, T.; Mende, D.R.; Fernandes, G.R.; Tap, J.; Bruls, T.; Batto, J.M.; et al. Enterotypes of the human gut microbiome. Nature 2011, 473, 174-180.

9. Tapiainen, T.; Ylitalo, S.; Eerola, E.; Uhari, M. Dynamics of gut colonization and source of intestinal flora in healthy newborn infants. APMIS 2006, 114, 812-817.

10. Koenig, J.E.; Spor, A.; Scalfone, N.; Fricker, A.D.; Stombaugh, J.; Knight, R.; Angenent, L.T.; Ley, R.E. Succession of microbial consortia in the developing infant gut microbiome. Proc. Natl. Acad. Sci. USA 2011, 108, 4578-4585.

11. Palmer, C.; Bik, E.M.; DiGiulio, D.B.; Relman, D.A.; Brown, P.O. Development of the human infant intestinal microbiota. PLoS Biol. 2007, 5, e177. 
12. Mackie, R.I.; Sghir, A.; Gaskins, H.R. Developmental microbial ecology of the neonatal gastrointestinal tract. Am. J. Clin. Nutr. 1999, 69, 1035S-1045S.

13. Koenig, J.E.; Spor, A.; Scalfone, N.; Fricker, A.D.; Stombaugh, J.; Knight, R.; Angenent, L.T.; Ley, R.E. Microbes and health sackler colloquium: Succession of microbial consortia in the developing infant gut microbiome. Proc. Natl. Acad. Sci. USA 2011, 108 (Suppl. 1), 4578-4585.

14. Rawls, J.F.; Mahowald, M.A.; Ley, R.E.; Gordon, J.I. Reciprocal gut microbiota transplants from zebrafish and mice to germ-free recipients reveal host habitat selection. Cell 2006, 127, 423-433.

15. Penders, J.; Thijs, C.; Vink, C.; Stelma, F.F.; Snijders, B.; Kummeling, I.; van den Brandt, P.A.; Stobberingh, E.E. Factors influencing the composition of the intestinal microbiota in early infancy. Pediatrics 2006, 118, 511-521.

16. Tanaka, S.; Kobayashi, T.; Songjinda, P.; Tateyama, A.; Tsubouchi, M.; Kiyohara, C.; Shirakawa, T.; Sonomoto, K.; Nakayama, J. Influence of antibiotic exposure in the early postnatal period on the development of intestinal microbiota. FEMS Immunol. Med. Microbiol. 2009, 56, 80-87.

17. Penders, J.; Vink, C.; Driessen, C.; London, N.; Thijs, C.; Stobberingh, E.E. Quantification of Bifidobacterium spp., Escherichia coli and Clostridium difficile in faecal samples of breast-fed and formula-fed infants by real-time PCR. FEMS Microbiol. Lett. 2005, 243, 141-147.

18. Turnbaugh, P.J.; Ridaura, V.K.; Faith, J.J.; Rey, F.E.; Knight, R.; Gordon, J.I. The effect of diet on the human gut microbiome: A metagenomic analysis in humanized gnotobiotic mice. Sci. Transl. Med. 2009, 1, doi:10.1126/scitranslmed.3000322.

19. O’Mahony, S.M.; Marchesi, J.R.; Scully, P.; Codling, C.; Ceolho, A.M.; Quigley, E.M.; Cryan, J.F.; Dinan, T.G. Early life stress alters behavior, immunity, and microbiota in rats: Implications for irritable bowel syndrome and psychiatric illnesses. Biol. Psychiatry 2009, 65, 263-267.

20. Bailey, M.T.; Lubach, G.R.; Coe, C.L. Prenatal stress alters bacterial colonization of the gut in infant monkeys. J. Pediatr. Gastroenterol. Nutr. 2004, 38, 414-421.

21. Hopkins, M.J.; Sharp, R.; Macfarlane, G.T. Variation in human intestinal microbiota with age. Dig. Liver Dis. 2002, 34, S12-S18.

22. Schmidt, B.; Mulder, I.E.; Musk, C.C.; Aminov, R.I.; Lewis, M.; Stokes, C.R.; Bailey, M.; Prosser, J.I.; Gill, B.P.; Pluske, J.R.; et al. Establishment of normal gut microbiota is compromised under excessive hygiene conditions. PLoS One 2011, 6, e28284.

23. Dethlefsen, L.; Eckburg, P.B.; Bik, E.M.; Relman, D.A. Assembly of the human intestinal microbiota. Trends Ecol. Evol. 2006, 21, 517-523.

24. Dominguez-Bello, M.G.; Costello, E.K.; Contreras, M.; Magris, M.; Hidalgo, G.; Fierer, N.; Knight, R. Delivery mode shapes the acquisition and structure of the initial microbiota across multiple body habitats in newborns. Proc. Natl. Acad. Sci. USA 2010, 107, 11971-11975.

25. Salminen, S.; Gibson, G.R.; McCartney, A.L.; Isolauri, E. Influence of mode of delivery on gut microbiota composition in seven year old children. Gut 2004, 53, 1388-1389.

26. Rakoff-Nahoum, S.; Medzhitov, R. Role of the innate immune system and host-commensal mutualism. Curr. Top. Microbiol. Immunol. 2006, 308, 1-18.

27. Xu, J.; Gordon, J.I. Inaugural article: Honor thy symbionts. Proc. Natl. Acad. Sci. USA 2003, $100,10452-10459$. 
28. Li, M.; Wang, B.; Zhang, M.; Rantalainen, M.; Wang, S.; Zhou, H.; Zhang, Y.; Shen, J.; Pang, X.; Wei, H.; et al. Symbiotic gut microbes modulate human metabolic phenotypes. Proc. Natl. Acad. Sci. USA 2008, 105, 2117-2122.

29. Tlaskalova-Hogenova, H.; Sterzl, J.; Stepankova, R.; Dlabac, V.; Veticka, V.; Rossmann, P.; Mandel, L.; Rejnek, J. Development of immunological capacity under germfree and conventional conditions. Ann. N. Y. Acad. Sci. 1983, 409, 96-113.

30. Moreau, M.C.; Ducluzeau, R.; Guy-Grand, D.; Muller, M.C. Increase in the population of duodenal immunoglobulin a plasmocytes in axenic mice associated with different living or dead bacterial strains of intestinal origin. Infect. Immun. 1978, 21, 532-539.

31. Imaoka, A.; Matsumoto, S.; Setoyama, H.; Okada, Y.; Umesaki, Y. Proliferative recruitment of intestinal intraepithelial lymphocytes after microbial colonization of germ-free mice. Eur. J. Immunol. 1996, 26, 945-948.

32. Sprinz, H.; Kundel, D.W.; Dammin, G.J.; Horowitz, R.E.; Schneider, H.; Formal, S.B. The response of the germfree guinea pig to oral bacterial challenge with Escherichia coli and Shigella flexneri. Am. J. Pathol. 1961, 39, 681-695.

33. Hrncir, T.; Stepankova, R.; Kozakova, H.; Hudcovic, T.; Tlaskalova-Hogenova, H. Gut microbiota and lipopolysaccharide content of the diet influence development of regulatory $\mathrm{T}$ cells: Studies in germ-free mice. BMC Immunol. 2008, 9, doi:10.1186/1471-2172-9-65.

34. Sjogren, Y.M.; Tomicic, S.; Lundberg, A.; Bottcher, M.F.; Bjorksten, B.; Sverremark-Ekstrom, E.; Jenmalm, M.C. Influence of early gut microbiota on the maturation of childhood mucosal and systemic immune responses. Clin. Exp. Allergy 2009, 39, 1842-1851.

35. Davis, C.P.; Savage, D.C. Habitat, succession, attachment, and morphology of segmented, filamentous microbes indigenous to the murine gastrointestinal tract. Infect. Immun. 1974, 10, 948-956.

36. Ivanov, I.I.; Atarashi, K.; Manel, N.; Brodie, E.L.; Shima, T.; Karaoz, U.; Wei, D.; Goldfarb, K.C.; Santee, C.A.; Lynch, S.V.; et al. Induction of intestinal th17 cells by segmented filamentous bacteria. Cell 2009, 139, 485-498.

37. Gaboriau-Routhiau, V.; Rakotobe, S.; Lecuyer, E.; Mulder, I.; Lan, A.; Bridonneau, C.; Rochet, V.; Pisi, A.; de Paepe, M.; Brandi, G.; et al. The key role of segmented filamentous bacteria in the coordinated maturation of gut helper t cell responses. Immunity 2009, 31, 677-689.

38. Mazmanian, S.K.; Liu, C.H.; Tzianabos, A.O.; Kasper, D.L. An immunomodulatory molecule of symbiotic bacteria directs maturation of the host immune system. Cell 2005, 122, 107-118.

39. Round, J.L.; Mazmanian, S.K. Inducible foxp3+ regulatory T-cell development by a commensal bacterium of the intestinal microbiota. Proc. Natl. Acad. Sci. USA 2010, 107, 12204-12209.

40. Frank, D.N.; St. Amand, A.L.; Feldman, R.A.; Boedeker, E.C.; Harpaz, N.; Pace, N.R. Molecular-Phylogenetic characterization of microbial community imbalances in human inflammatory bowel diseases. Proc. Natl. Acad. Sci. USA 2007, 104, 13780-13785.

41. Atarashi, K.; Honda, K. Microbiota in autoimmunity and tolerance. Curr. Opin. Immunol. 2011, 23, 761-768.

42. Donohoe, D.R.; Garge, N.; Zhang, X.; Sun, W.; O’Connell, T.M.; Bunger, M.K.; Bultman, S.J. The microbiome and butyrate regulate energy metabolism and autophagy in the mammalian colon. Cell Metab. 2011, 13, 517-526. 
43. El-Ansary, A.K.; Ben Bacha, A.; Kotb, M. Etiology of autistic features: The persisting neurotoxic effects of propionic acid. J. Neuroinflamm. 2012, 9, 74.

44. Fallani, M.; Young, D.; Scott, J.; Norin, E.; Amarri, S.; Adam, R.; Aguilera, M.; Khanna, S.; Gil, A.; Edwards, C.A.; et al. Intestinal microbiota of 6-week-old infants across europe: Geographic influence beyond delivery mode, breast-feeding, and antibiotics. J. Pediatr. Gastroenterol. Nutr. 2010, 51, 77-84.

45. Zhang, C.; Zhang, M.; Wang, S.; Han, R.; Cao, Y.; Hua, W.; Mao, Y.; Zhang, X.; Pang, X.; Wei, C.; et al. Interactions between gut microbiota, host genetics and diet relevant to development of metabolic syndromes in mice. ISME J. 2010, 4, 232-241.

46. Sekirov, I.; Russell, S.; Caetano, L.; Antunes, M.; Finlay, B.B. Gut microbiota in health and disease. Am. Physiol. Soc. 2010, 90, 859-904.

47. Walker, A.W.; Ince, J.; Duncan, S.H.; Webster, L.M.; Holtrop, G.; Ze, X.; Brown, D.; Stares, M.D.; Scott, P.; Bergerat, A.; et al. Dominant and diet-responsive groups of bacteria within the human colonic microbiota. ISME J. 2011, 5, 220-230.

48. Santacruz, A.; Marcos, A.; Warnberg, J.; Marti, A.; Martin-Matillas, M.; Campoy, C.; Moreno, L.A.; Veiga, O.; Redondo-Figuero, C.; Garagorri, J.M.; et al. Interplay between weight loss and gut microbiota composition in overweight adolescents. Obesity (Silver Spring) 2009, 17, 1906-1915.

49. Walker, A.W.; Sanderson, J.D.; Churcher, C.; Parkes, G.C.; Hudspith, B.N.; Rayment, N.; Brostoff, J.; Parkhill, J.; Dougan, G.; Petrovska, L. High-Throughput clone library analysis of the mucosa-associated microbiota reveals dysbiosis and differences between inflamed and non-inflamed regions of the intestine in inflammatory bowel disease. BMC Microbiol. 2011, 11, 7.

50. Smith, E.; Macfarlane, G.T. Dissimilatory amino acid metabolism in human colonic metabolism. Anaerobe 1997, 3, 327-337.

51. Cummings, J.; Hill, M.J.; Bones, E.S.; Branch, W.J.; Jenkins, D.J. The effect of meat protein and dietary fiber on colonic function and metabolism. II. Bacterial metabolites in feces and urine. Am. J. Clin. Nutr. 1979, 32, 2094-2101.

52. Birkett, A.; Muir, J.; Phillips, J.; Jones, G.; O’Dea, K. Resistant starch lowers fecal concentrations of ammonia and phenols in humans. Am. J. Clin. Nutr. 1996, 63, 766-772.

53. Pokusaeva, K.; Fitzgerald, G.F.; van Sinderen, D. Carbohydrate metabolism in bifidobacteria. Genes Nutr. 2011, 6, 285-306.

54. Berg, A.M.; Kelly, C.P.; Farraye, F.A. Clostridium difficile infection in the inflammatory bowel disease patient. Inflamm. Bowel Dis. 2012, doi:10.1002/ibd.22964.

55. Begley, M.; Hill, C.; Gahan, C.G. Bile salt hydrolase activity in probiotics. Appl. Environ. Microbiol. 2006, 72, 1729-1738.

56. Zimmer, J.; Lange, B.; Frick, J.S.; Sauer, H.; Zimmermann, K.; Schwiertz, A.; Rusch, K.; Klosterhalfen, S.; Enck, P. A vegan or vegetarian diet substantially alters the human colonic faecal microbiota. Eur. J. Clin. Nutr. 2012, 66, 53-60.

57. De Filippo, C.; Cavalieri, D.; Di Paola, M.; Ramazzotti, M.; Poullet, J.B.; Massart, S.; Collini, S.; Pieraccini, G.; Lionetti, P. Impact of diet in shaping gut microbiota revealed by a comparative study in children from europe and rural africa. Proc. Natl. Acad. Sci. USA 2010, 107, 14691-14696. 
58. Mozes, S.; Bujnakova, D.; Sefcikova, Z.; Kmet, V. Developmental changes of gut microflora and enzyme activity in rat pups exposed to fat-rich diet. Obesity (Silver Spring) 2008, 16, 2610-2615.

59. Turnbaugh, P.J.; Backhed, F.; Fulton, L.; Gordon, J.I. Diet-Induced obesity is linked to marked but reversible alterations in the mouse distal gut microbiome. Cell Host Microbe 2008, 3, 213-223.

60. De la Serre, C.; Ellis, C.L.; Lee, J.; Hartman, A.L.; Rutledge, J.C.; Raybould, H.E. Propensity to high-fat diet-induced obesity in rats is associated with changes in the gut microbiota and gut inflammation. Am. J. Physiol. 2010, 299, G440-G448.

61. Hildebrandt, M.A.; Hoffmann, C.; Sherrill-Mix, S.A.; Keilbaugh, S.A.; Hamady, M.; Chen, Y.Y.; Knight, R.; Ahima, R.S.; Bushman, F.; Wu, G.D. High-Fat diet determines the composition of the murine gut microbiome independently of obesity. Gastroenterology 2009, 137, 1716-1724.

62. Devkota, S.; Wang, Y.; Musch, M. Dietary-Fat-Induced taurocholic acid promotes pathobiont expansion and colitis in $I I 10^{-/-}$mice. Nature 2012, doi:10.1038/nature11225.

63. Gorbach, S.L. Bengt E. gustafsson memorial lecture. Function of the normal human microflora. Scand. J. Infect. Dis. Suppl. 1986, 49, 17-30.

64. Flint, H.; Scott, K.; Duncan, S.; Louis, P.; Forano, E. Microbial degradation of complex carbohydrates in the gut. Gut Microbes 2012, 3, doi.10.4161/gmic.19897.

65. Parnell, J.A.; Reimer, R.A. Prebiotic fiber modulation of the gut microbiota improves risk factors for obesity and the metabolic syndrome. Gut Microbes 2012, 3, 29-34.

66. Martens, E.C.; Lowe, E.C.; Chiang, H.; Pudlo, N.A.; Wu, M.; McNulty, N.P.; Abbott, D.W.; Henrissat, B.; Gilbert, H.J.; Bolam, D.N.; et al. Recognition and degradation of plant cell wall polysaccharides by two human gut symbionts. PLoS Biol. 2011, 9, e1001221.

67. Tremellen, K.; Pearce, K. Dysbiosis of gut microbiota (dogma) - a novel theory for the development of polycystic ovarian syndrome. Med. Hypotheses 2012, 79, 104-112.

68. Nielsen, S.; Nielsen, D.S.; Lauritzen, L.; Jakobsen, M.; Michaelsen, K.F. Impact of diet on the intestinal microbiota in 10-month-old infants. J. Pediatr. Gastroenterol. Nutr. 2007, 44, 613-618.

69. Murphy, E.F.; Cotter, P.D.; Healy, S.; Marques, T.M.; O’Sullivan, O.; Fouhy, F.; Clarke, S.F.; O'Toole, P.W.; Quigley, E.M.; Stanton, C.; et al. Composition and energy harvesting capacity of the gut microbiota: Relationship to diet, obesity and time in mouse models. Gut 2010, 59, $1635-1642$.

70. Turnbaugh, P.J.; Ley, R.E.; Mahowald, M.A.; Magrini, V.; Mardis, E.R.; Gordon, J.I. An obesity-associated gut microbiome with increased capacity for energy harvest. Nature 2006, 444, 1027-1031.

71. Aronson, D.; Bartha, P.; Zinder, O.; Kerner, A.; Markiewicz, W.; Avizohar, O.; Brook, G.J.; Levy, Y. Obesity is the major determinant of elevated C-reactive protein in subjects with the metabolic syndrome. Int. J. Obes. Relat. Metab. Disord. 2004, 28, 674-679.

72. Backhed, F.; Ding, H.; Wang, T.; Hooper, L.V.; Koh, G.Y.; Nagy, A.; Semenkovich, C.F.; Gordon, J.I. The gut microbiota as an environmental factor that regulates fat storage. Proc. Natl. Acad. Sci. USA 2004, 101, 15718-15723. 
73. Karlsson, C.L.; Onnerfalt, J.; Xu, J.; Molin, G.; Ahrne, S.; Thorngren-Jerneck, K. The microbiota of the gut in preschool children with normal and excessive body weight. Obesity (Silver Spring) 2012, doi:10.1038/oby.2012.110.

74. Million, M.; Angelakis, E.; Paul, M.; Armougom, F.; Leibovici, L.; Raoult, D. Comparative meta-analysis of the effect of lactobacillus species on weight gain in humans and animals. Microb. Pathog. 2012, 53, 100-108.

75. Cani, P.D.; Possemiers, S.; van de Wiele, T.; Guiot, Y.; Everard, A.; Rottier, O.; Geurts, L.; Naslain, D.; Neyrinck, A.; Lambert, D.M.; et al. Changes in gut microbiota control inflammation in obese mice through a mechanism involving GLP-2-driven improvement of gut permeability. Gut 2009, 58, 1091-1103.

76. Duncan, S.H.; Lobley, G.E.; Holtrop, G.; Ince, J.; Johnstone, A.M.; Louis, P.; Flint, H.J. Human colonic microbiota associated with diet, obesity and weight loss. Int. J. Obes. (Lond.) 2008, 32, $1720-1724$.

77. Schweirtz, A.; Taras, D.; Schäfer, K.; Beijer, S.; Bos, N.A.; Donus, C.; Hardt, P.D. Microbiota and SCFA in lean and overweight healthy subjects. Obesity 2010, 18, 190-195.

78. Rabot, S.; Membrez, M.; Bruneau, A.; Gerard, P.; Harach, T.; Moser, M.; Raymond, F.; Mansourian, R.; Chou, C.J. Germ-Free C57BL/6J mice are resistant to high-fat-diet-induced insulin resistance and have altered cholesterol metabolism. FASEB J. 2010, 24, 4948-4959.

79. Murphy, E.F.; Cotter, P.D.; Hogan, A.; O’Sullivan, O.; Joyce, A.; Fouhy, F.; Clarke, S.F.; Marques, T.M.; O’Toole, P.W.; Stanton, C.; et al. Divergent metabolic outcomes arising from targeted manipulation of the gut microbiota in diet-induced obesity. Gut 2012, doi:10.1136/ gutjnl-2011-300705.

80. Larsen, N.; Vogensen, F.K.; van den Berg, F.W.; Nielsen, D.S.; Andreasen, A.S.; Pedersen, B.K.; Al-Soud, W.A.; Sorensen, S.J.; Hansen, L.H.; Jakobsen, M. Gut microbiota in human adults with type 2 diabetes differs from non-diabetic adults. PLoS One 2010, 5, e9085.

81. Cani, P.D.; Amar, J.; Iglesias, M.A.; Poggi, M.; Knauf, C.; Bastelica, D.; Neyrinck, A.M.; Fava, F.; Tuohy, K.M.; Chabo, C.; et al. Metabolic endotoxemia initiates obesity and insulin resistance. Diabetes 2007, 56, 1761-1772.

82. Pendyala, S.; Walker, J.M.; Holt, P.R. A high-fat diet is associated with endotoxemia that originates from the gut. Gastroenterology 2012, 142, 1100-1101.

83. Caesar, R.; Reigstad, C.S.; Backhed, H.K.; Reinhardt, C.; Ketonen, M.; Ostergren Lunden, G.; Cani, P.D.; Backhed, F. Gut-Derived lipopolysaccharide augments adipose macrophage accumulation but is not essential for impaired glucose or insulin tolerance in mice. Gut 2012, doi:10.1136/gutjnl-2011-301689.

84. Creely, S.J.; McTernan, P.G.; Kusminski, C.M.; Fisher, M.; Da Silva, N.F.; Khanolkar, M.; Evans, M.; Harte, A.L.; Kumar, S. Lipopolysaccharide activates an innate immune system response in human adipose tissue in obesity and type 2 diabetes. Am. J. Physiol. Endocrinol. Metab. 2007, 292, E740-E747.

85. Tehrani, A.B.; Nezami, B.G.; Gewirtz, A.; Srinivasan, S. Obesity and its associated disease: A role for microbiota? Neurogastroenterol. Motil. 2012, 24, 305-311. 
86. Vijay-Kumar, M.; Aitken, J.D.; Carvalho, F.A.; Kumar, M.V.; Aitken, J.D.; Carvalho, F.A.; Cullender, T.C.; Mwangi, S.; Srinivasan, S.; Sitaraman, S.V.; et al. Metabolic syndrome and altered gut microbiota in mice lacking toll-like receptor 5. Science 2010, 328, 228-231.

87. Amar, J.; Chabo, C.; Waget, A.; Klopp, P.; Vachoux, C.; Bermudez-Humaran, L.G.; Smirnova, N.; Berge, M.; Sulpice, T.; Lahtinen, S.; et al. Intestinal mucosal adherence and translocation of commensal bacteria at the early onset of type 2 diabetes: Molecular mechanisms and probiotic treatment. EMBO Mol. Med. 2011, 3, 559-572.

88. Cani, P.D.; Delzenne, N.M. The gut microbiome as therapeutic target. Pharmacol. Ther. 2011, 130, 202-212.

89. Parnell, J.A.; Reimer, R.A. Prebiotic fiber modulation of the gut microbiota improves risk factors for obesity and the metabolic syndrome. Gut Microbes 2012, 3, 29-34.

90. Ley, R.E. Obesity and the human microbiome. Curr. Opin. Gastroenterol. 2010, 26, 5-11.

91. Pozzilli, P.; Signore, A.; Williams, A.J.; Beales, P.E. Nod mouse colonies around the world-Recent facts and figures. Immunol. Today 1993, 14, 193-196.

92. Roesch, L.F.; Lorca, G.L.; Casella, G.; Giongo, A.; Naranjo, A.; Pionzio, A.M.; Li, N.; Mai, V.; Wasserfall, C.H.; Schatz, D.; et al. Culture-Independent identification of gut bacteria correlated with the onset of diabetes in a rat model. ISME J. 2009, 3, 536-548.

93. Wen, L.; Ley, R.E.; Volchkov, P.Y.; Stranges, P.B.; Avanesyan, L.; Stonebraker, A.C.; Hu, C.; Wong, F.S.; Szot, G.L.; Bluestone, J.A.; et al. Innate immunity and intestinal microbiota in the development of type 1 diabetes. Nature 2008, 455, 1109-1113.

94. Giongo, A.; Gano, K.A.; Crabb, D.B.; Mukherjee, N.; Novelo, L.L.; Casella, G.; Drew, J.C.; Ilonen, J.; Knip, M.; Hyoty, H.; et al. Toward defining the autoimmune microbiome for type 1 diabetes. ISME J. 2011, 5, 82-91.

95. Sapone, A.; de Magistris, L.; Pietzak, M.; Clemente, M.G.; Tripathi, A.; Cucca, F.; Lampis, R.; Kryszak, D.; Carteni, M.; Generoso, M.; et al. Zonulin upregulation is associated with increased gut permeability in subjects with type 1 diabetes and their relatives. Diabetes 2006, 55, $1443-1449$.

96. Lee, A.S.; Gibson, D.L.; Zhang, Y.; Sham, H.P.; Vallance, B.A.; Dutz, J.P. Gut barrier disruption by an enteric bacterial pathogen accelerates insulitis in nod mice. Diabetologia 2010, 53, 741-748.

97. Bosi, E.; Molteni, L.; Radaelli, M.G.; Folini, L.; Fermo, I.; Bazzigaluppi, E.; Piemonti, L.; Pastore, M.R.; Paroni, R. Increased intestinal permeability precedes clinical onset of type 1 diabetes. Diabetologia 2006, 49, 2824-2827.

98. Watts, T.; Berti, I.; Sapone, A.; Gerarduzzi, T.; Not, T.; Zielke, R.; Fasano, A. Role of the intestinal tight junction modulator zonulin in the pathogenesis of type I diabetes in BB diabetic-prone rats. Proc. Natl. Acad. Sci. USA 2005, 102, 2916-2921.

99. Kriegel, M.A.; Sefik, E.; Hill, J.A.; Wu, H.J.; Benoist, C.; Mathis, D. Naturally transmitted segmented filamentous bacteria segregate with diabetes protection in nonobese diabetic mice. Proc. Natl. Acad. Sci. USA 2011, 108, 11548-11553.

100. Alam, C.; Bittoun, E.; Bhagwat, D.; Valkonen, S.; Saari, A.; Jaakkola, U.; Eerola, E.; Huovinen, P.; Hanninen, A. Effects of a germ-free environment on gut immune regulation and diabetes progression in non-obese diabetic (nod) mice. Diabetologia 2011, 54, 1398-1406. 
101. Valladares, R.; Sankar, D.; Li, N.; Williams, E.; Lai, K.K.; Abdelgeliel, A.S.; Gonzalez, C.F.; Wasserfall, C.H.; Larkin, J.; Schatz, D.; et al. Lactobacillus johnsonii N6.2 mitigates the development of type 1 diabetes in BB-DP rats. PLoS One 2010, 5, e10507.

102. Lau, K.; Benitez, P.; Ardissone, A.; Wilson, T.D.; Collins, E.L.; Lorca, G.; Li, N.; Sankar, D.; Wasserfall, C.; Neu, J.; et al. Inhibition of type 1 diabetes correlated to a Lactobacillus johnsonii N6.2-mediated TH17 bias. J. Immunol. 2011, 186, 3538-3546.

103. Calcinaro, F.; Dionisi, S.; Marinaro, M.; Candeloro, P.; Bonato, V.; Marzotti, S.; Corneli, R.B.; Ferretti, E.; Gulino, A.; Grasso, F.; et al. Oral probiotic administration induces interleukin-10 production and prevents spontaneous autoimmune diabetes in the non-obese diabetic mouse. Diabetologia 2005, 48, 1565-1575.

104. Alves, J.G.; Figueiroa, J.N.; Meneses, J.; Alves, G.V. Breastfeeding protects against type 1 diabetes mellitus: A case-sibling study. Breastfeed. Med. 2012, 7, 25-28.

105. Kunz, C.; Rudloff, S.; Baier, W.; Klein, N.; Strobel, S. Oligosaccharides in human milk: Structural, functional, and metabolic aspects. Annu. Rev. Nutr. 2000, 20, 699-722.

106. Bode, L. Human milk oligosaccharides: Prebiotics and beyond. Nutr. Rev. 2009, 67, S183-S191.

107. Benson, V.S.; Vanleeuwen, J.A.; Taylor, J.; McKinney, P.A.; van Til, L. Food consumption and the risk of type 1 diabetes in children and youth: A population-based, case-control study in Prince Edward Island, Canada. J. Am. Coll. Nutr. 2008, 27, 414-420.

108. Virtanen, S.M.; Nevalainen, J.; Kronberg-Kippila, C.; Ahonen, S.; Tapanainen, H.; Uusitalo, L.; Takkinen, H.M.; Niinisto, S.; Ovaskainen, M.L.; Kenward, M.G.; et al. Food consumption and advanced beta cell autoimmunity in young children with HLA-conferred susceptibility to type 1 diabetes: A nested case-control design. Am. J. Clin. Nutr. 2012, 95, 471-478.

109. Chamson-Reig, A.; Arany, E.J.; Summers, K.; Hill, D.J. A low protein diet in early life delays the onset of diabetes in the non-obese diabetic mouse. J. Endocrinol. 2009, 201, 231-239.

110. Bahr, J.; Kloting, N.; Wilke, B.; Kloting, I.; Follak, N. High-Fat diet protects BB/OK rats from developing type 1 diabetes. Diabetes Metab. Res. Rev. 2011, 27, 552-556.

111. Kagohashi, Y.; Otani, H. Diet with a low $n-6 / n-3$ essential fatty acid ratio when started immediately after the onset of overt diabetes prolongs survival of type 1 diabetes model NOD mice. Congenit. Anom. (Kyoto) 2010, 50, 226-231.

112. Alam, C.; Valkonen, S.; Palagani, V.; Jalava, J.; Eerola, E.; Hanninen, A. Inflammatory tendencies and overproduction of IL-17 in the colon of young nod mice are counteracted with diet change. Diabetes 2010, 59, 2237-2246.

113. Rakoff-Nahoum, S.; Paglino, J.; Eslami-Varzaneh, F.; Edberg, S.; Medzhitov, R. Recognition of commensal microflora by toll-like receptors is required for intestinal homeostasis. Cell 2004, 118, 229-241.

114. Garrett, W.S.; Lord, G.M.; Punit, S.; Lugo-Villarino, G.; Mazmanian, S.K.; Ito, S.; Glickman, J.N.; Glimcher, L.H. Communicable ulcerative colitis induced by T-bet deficiency in the innate immune system. Cell 2007, 131, 33-45.

115. Nishikawa, J.; Kudo, T.; Sakata, S.; Benno, Y.; Sugiyama, T. Diversity of mucosa-associated microbiota in active and inactive ulcerative colitis. Scand. J. Gastroenterol. 2009, 44, 180-186. 
116. Andoh, A.; Sakata, S.; Koizumi, Y.; Mitsuyama, K.; Fujiyama, Y.; Benno, Y. Terminal restriction fragment length polymorphism analysis of the diversity of fecal microbiota in patients with ulcerative colitis. Inflamm. Bowel Dis. 2007, 13, 955-962.

117. Gophna, U.; Sommerfeld, K.; Gophna, S.; Doolittle, W.F.; Veldhuyzen van Zanten, S.J. Differences between tissue-associated intestinal microfloras of patients with Crohn's disease and ulcerative colitis. J. Clin. Microbiol. 2006, 44, 4136-4141.

118. Sokol, H.; Lepage, P.; Seksik, P.; Dore, J.; Marteau, P. Temperature gradient gel electrophoresis of fecal 16S rRNA reveals active Escherichia coli in the microbiota of patients with ulcerative colitis. J. Clin. Microbiol. 2006, 44, 3172-3177.

119. Mondot, S.; Kang, S.; Furet, J.P.; Aguirre de Carcer, D.; McSweeney, C.; Morrison, M.; Marteau, P.; Dore, J.; Leclerc, M. Highlighting new phylogenetic specificities of Crohn's disease microbiota. Inflamm. Bowel Dis. 2011, 17, 185-192.

120. Chapkin, R.S.; Davidson, L.A.; Ly, L.; Weeks, B.R.; Lupton, J.R.; McMurray, D.N. Immunomodulatory effects of $(n-3)$ fatty acids: Putative link to inflammation and colon cancer. J. Nutr. 2007, 137, 200S-204S.

121. Asakura, H.; Suzuki, K.; Kitahora, T.; Morizane, T. Is there a link between food and intestinal microbes and the occurrence of Crohn's disease and ulcerative colitis? J. Gastroenterol. Hepatol. 2008, 23, 1794-1801.

122. Tjonneland, A.; Overvad, K.; Bergmann, M.M.; Nagel, G.; Linseisen, J.; Hallmans, G.; Palmqvist, R.; Sjodin, H.; Hagglund, G.; Berglund, G.; et al. Linoleic acid, a dietary n-6 polyunsaturated fatty acid, and the aetiology of ulcerative colitis: A nested case-control study within a European prospective cohort study. Gut 2009, 58, 1606-1611.

123. Uchiyama, K.; Nakamura, M.; Odahara, S.; Koido, S.; Katahira, K.; Shiraishi, H.; Ohkusa, T.; Fujise, K.; Tajiri, H. N-3 polyunsaturated fatty acid diet therapy for patients with inflammatory bowel disease. Inflamm. Bowel Dis. 2010, 16, 1696-1707.

124. Wallace, D.F.; Crawford, D.H.; Subramaniam, V.N. The control of iron homeostasis: Micrornas join the party. Gastroenterology 2011, 141, 1520-1522.

125. Ma, X.; Torbenson, M.; Hamad, A.R.; Soloski, M.J.; Li, Z. High-Fat diet modulates non-CD1d-restricted natural killer $\mathrm{T}$ cells and regulatory $\mathrm{T}$ cells in mouse colon and exacerbates experimental colitis. Clin. Exp. Immunol. 2008, 151, 130-138.

126. Matsunaga, H.; Hokari, R.; Kurihara, C.; Okada, Y.; Takebayashi, K.; Okudaira, K.; Watanabe, C.; Komoto, S.; Nakamura, M.; Tsuzuki, Y.; et al. Omega-3 fatty acids exacerbate DSS-induced colitis through decreased adiponectin in colonic subepithelial myofibroblasts. Inflamm. Bowel Dis. 2008, 14, 1348-1357.

127. Innis, S.M.; Dai, C.; Wu, X.; Buchan, A.M.; Jacobson, K. Perinatal lipid nutrition alters early intestinal development and programs the response to experimental colitis in young adult rats. Am. J. Physiol. Gastrointest. Liver Physiol. 2010, 299, G1376-G1385.

128. Meijer, B.J.; Dieleman, L.A. Probiotics in the treatment of human inflammatory bowel diseases: Update 2011. J. Clin. Gastroenterol. 2011, 45, S139-S144.

129. Dahlqvist, G.; Piessevaux, H. Irritable bowel syndrome: The role of the intestinal microbiota, pathogenesis and therapeutic targets. Acta Gastroenterol. Belg. 2011, 74, 375-380. 
130. Kassinen, A.; Krogius-Kurikka, L.; Makivuokko, H.; Rinttila, T.; Paulin, L.; Corander, J.; Malinen, E.; Apajalahti, J.; Palva, A. The fecal microbiota of irritable bowel syndrome patients differs significantly from that of healthy subjects. Gastroenterology 2007, 133, 24-33.

131. Codling, C.; O’Mahony, L.; Shanahan, F.; Quigley, E.M.; Marchesi, J.R. A molecular analysis of fecal and mucosal bacterial communities in irritable bowel syndrome. Dig. Dis. Sci. 2010, 55, 392-397.

132. Lee, K.J.; Tack, J. Altered intestinal microbiota in irritable bowel syndrome. Neurogastroenterol. Motil. 2010, 22, 493-498.

133. Rajilic-Stojanovic, M.; Biagi, E.; Heilig, H.G.; Kajander, K.; Kekkonen, R.A.; Tims, S.; de Vos, W.M. Global and deep molecular analysis of microbiota signatures in fecal samples from patients with irritable bowel syndrome. Gastroenterology 2011, 141, 1792-1801.

134. Jeffery, I.B.; O’Toole, P.W.; Ohman, L.; Claesson, M.J.; Deane, J.; Quigley, E.M.; Simren, M. An irritable bowel syndrome subtype defined by species-specific alterations in faecal microbiota. Gut 2012, 61, 997-1006.

135. Malinen, E.; Rinttila, T.; Kajander, K.; Matto, J.; Kassinen, A.; Krogius, L.; Saarela, M.; Korpela, R.; Palva, A. Analysis of the fecal microbiota of irritable bowel syndrome patients and healthy controls with real-time PCR. Am. J. Gastroenterol. 2005, 100, 373-382.

136. Kerckhoffs, A.P.; Samsom, M.; van der Rest, M.E.; de Vogel, J.; Knol, J.; Ben-Amor, K.; Akkermans, L.M. Lower bifidobacteria counts in both duodenal mucosa-associated and fecal microbiota in irritable bowel syndrome patients. World J. Gastroenterol. 2009, 15, 2887-2892.

137. Ponnusamy, K.; Choi, J.N.; Kim, J.; Lee, S.Y.; Lee, C.H. Microbial community and metabolomic comparison of irritable bowel syndrome faeces. J. Med. Microbiol. 2011, 60, 817-827.

138. Matto, J.; Maunuksela, L.; Kajander, K.; Palva, A.; Korpela, R.; Kassinen, A.; Saarela, M. Composition and temporal stability of gastrointestinal microbiota in irritable bowel syndrome-A longitudinal study in IBS and control subjects. FEMS Immunol. Med. Microbiol. 2005, 43, 213-222.

139. Kerckhoffs, A.P.; Ben-Amor, K.; Samsom, M.; van der Rest, M.E.; de Vogel, J.; Knol, J.; Akkermans, L.M. Molecular analysis of faecal and duodenal samples reveals significantly higher prevalence and numbers of Pseudomonas aeruginosa in irritable bowel syndrome. J. Med. Microbiol. 2011, 60, 236-245.

140. Saulnier, D.M.; Riehle, K.; Mistretta, T.A.; Diaz, M.A.; Mandal, D.; Raza, S.; Weidler, E.M.; Qin, X.; Coarfa, C.; Milosavljevic, A.; et al. Gastrointestinal microbiome signatures of pediatric patients with irritable bowel syndrome. Gastroenterology 2011, 141, 1782-1791.

141. Parkes, G.C.; Rayment, N.B.; Hudspith, B.N.; Petrovska, L.; Lomer, M.C.; Brostoff, J.; Whelan, K.; Sanderson, J.D. Distinct microbial populations exist in the mucosa-associated microbiota of sub-groups of irritable bowel syndrome. Neurogastroenterol. Motil. 2012, 24, 31-39.

142. Krogius-Kurikka, L.; Lyra, A.; Malinen, E.; Aarnikunnas, J.; Tuimala, J.; Paulin, L.; Makivuokko, H.; Kajander, K.; Palva, A. Microbial community analysis reveals high level phylogenetic alterations in the overall gastrointestinal microbiota of diarrhoea-predominant irritable bowel syndrome sufferers. BMC Gastroenterol. 2009, 9, 95. 
143. Carroll, I.M.; Ringel-Kulka, T.; Siddle, J.P.; Ringel, Y. Alterations in composition and diversity of the intestinal microbiota in patients with diarrhea-predominant irritable bowel syndrome. Neurogastroenterol. Motil. 2012, 24, 521-530.

144. Chassard, C.; Dapoigny, M.; Scott, K.P.; Crouzet, L.; Del'homme, C.; Marquet, P.; Martin, J.C.; Pickering, G.; Ardid, D.; Eschalier, A.; et al. Functional dysbiosis within the gut microbiota of patients with constipated-irritable bowel syndrome. Aliment. Pharmacol. Ther. 2012, 35, 828-838.

145. Brint, E.K.; MacSharry, J.; Fanning, A.; Shanahan, F.; Quigley, E.M. Differential expression of toll-like receptors in patients with irritable bowel syndrome. Am. J. Gastroenterol. 2011, 106, 329-336.

146. Tarrerias, A.L.; Costil, V.; Vicari, F.; Letard, J.C.; Adenis-Lamarre, P.; Aisene, A.; Batistelli, D.; Bonnaud, G.; Carpentier, S.; Dalbies, P.; et al. The effect of inactivated Lactobacillus LB fermented culture medium on symptom severity: Observational investigation in 297 patients with diarrhea-predominant irritable bowel syndrome. Dig. Dis. 2011, 29, 588-591.

147. Simren, M.; Mansson, A.; Langkilde, A.M.; Svedlund, J.; Abrahamsson, H.; Bengtsson, U.; Bjornsson, E.S. Food-Related gastrointestinal symptoms in the irritable bowel syndrome. Digestion 2001, 63, 108-115.

148. Gibson, D.L.; Vallance, B.A. Intestinal microbiota are transiently altered during salmonella-induced gastroenteritis. Expert Rev. Gastroenterol. Hepatol. 2008, 2, 525-529.

149. Ki Cha, B.; Mun Jung, S.; Hwan Choi, C.; Song, I.D.; Woong Lee, H.; Joon Kim, H.; Hyuk, J.; Kyung Chang, S.; Kim, K.; Chung, W.S.; et al. The effect of a multispecies probiotic mixture on the symptoms and fecal microbiota in diarrhea-dominant irritable bowel syndrome: A randomized, double-blind, placebo-controlled trial. J. Clin. Gastroenterol. 2012, 46, 220-227.

150. Guglielmetti, S.; Mora, D.; Gschwender, M.; Popp, K. Randomised clinical trial: Bifidobacterium bifidum MIMBb75 significantly alleviates irritable bowel syndrome and improves quality of life-A double-blind, placebo-controlled study. Aliment. Pharmacol. Ther. 2011, 33, 1123-1132.

151. Silk, D.B.; Davis, A.; Vulevic, J.; Tzortzis, G.; Gibson, G.R. Clinical trial: The effects of a trans-galactooligosaccharide prebiotic on faecal microbiota and symptoms in irritable bowel syndrome. Aliment. Pharmacol. Ther. 2009, 29, 508-518.

152. Diosdado, B.; van Oort, E.; Wijmenga, C. Coelionomics: Towards understanding the molecular pathology of celiac disease. Clin. Chem. Lab. Med. 2005, 43, 685-695.

153. Sollid, L. Celiac disease as a model of gastrointestinal inflammation. J. Pediatr. Gastroenterol. Nutr. 2005, 40, S41-S42.

154. Palma, G.D.; Capilla, A.; Nova, E.; Castillejo, G.; Varea, V.; Pozo, T.; Garrote, J.A.; Polanco, I.; Lopez, A.; Ribes-Koninckx, C.; et al. Influence of milk-feeding type and genetic risk of developing coeliac disease on intestinal microbiota of infants: The proficel study. PLoS One 2012, 7, e30791.

155. Decker, E.; Hornef, M.; Stockinger, S. Cesarean delivery is associated with celiac disease but not inflammatory bowel disease in children. Gut Microbes 2011, 2, 91-98.

156. De Palma, G.; Nadal, I.; Medina, M.; Donat, E.; Ribes-Koninckx, C.; Calabuig, M.; Sanz, Y. Intestinal dysbiosis and reduced immunoglobulin-coated bacteria associated with coeliac disease in children. BMC Microbiol. 2010, 10, doi:10.1186/1471-2180-10-63. 
157. Nistal, E.; Caminero, A.; Vivas, S.; Ruiz de Morales, J.M.; Saenz de Miera, L.E.; Rodriguez-Aparicio, L.B.; Casqueiro, J. Differences in faecal bacteria populations and faecal bacteria metabolism in healthy adults and celiac disease patients. Biochimie 2012, 94, 1724-1729.

158. Di Cagno, R.; de Angelis, M.; de Pasquale, I.; Ndagijimana, M.; Vernocchi, P.; Ricciuti, P.; Gagliardi, F.; Laghi, L.; Crecchio, C.; Guerzoni, M.E.; et al. Duodenal and faecal microbiota of celiac children: Molecular, phenotype and metabolome characterization. BMC Microbiol. 2011, 11, doi:10.1186/1471-2180-11-219.

159. Sanz, Y.; de Pama, G.; Laparra, M. Unraveling the ties between celiac disease and intestinal microbiota. Int. Rev. Immunol. 2011, 30, 207-218.

160. De Palma, G.; Nadal, I.; Collado, M.C.; Sanz, Y. Effects of a gluten-free diet on gut microbiota and immune function in healthy adult human subjects. Br. J. Nutr. 2009, 102, 1154-1160.

161. Collado, M.C.; Donat, E.; Ribes-Koninckx, C.; Calabuig, M.; Sanz, Y. Specific duodenal and faecal bacterial groups associated with paediatric coeliac disease. J. Clin. Pathol. 2009, 62, 264-269.

162. Sanz, Y.; Sanchez, E.; Marzotto, M.; Calabuig, M.; Torriani, S.; Dellaglio, F. Differences in faecal bacterial communities in coeliac and healthy children as detected by PCR and denaturing gradient gel electrophoresis. FEMS Immunol. Med. Microbiol. 2007, 51, 562-568.

163. Laparra, J.M.; Olivares, M.; Gallina, O.; Sanz, Y. Bifidobacterium longum cect 7347 modulates immune responses in a gliadin-induced enteropathy animal model. PLoS One 2012, 7, e30744.

164. Nadal, I.; Donat, E.; Ribes-Koninckx, C.; Calabuig, M.; Sanz, Y. Imbalance in the composition of the duodenal microbiota of children with coeliac disease. J. Med. Microbiol. 2007, 56, 1669-1674.

165. Kalliomaki, M.; Satokari, R.; Lahteenoja, H.; Vahamiko, S.; Gronlund, J.; Routi, T.; Salminen, S. Expression of microbiota, toll-like receptors, and their regulators in the small intestinal mucosa in celiac disease. J. Pediatr. Gastroenterol. Nutr. 2012, 54, 727-732.

166. Nistal, E.; Caminero, A.; Herran, A.R.; Arias, L.; Vivas, S.; de Morales, J.M.; Calleja, S.; de Miera, L.E.; Arroyo, P.; Casqueiro, J. Differences of small intestinal bacteria populations in adults and children with/without celiac disease: Effect of age, gluten diet, and disease. Inflamm. Bowel Dis. 2012, 18, 649-656.

167. D’Arienzo, R.; Stefanile, R.; Maurano, F.; Mazzarella, G.; Ricca, E.; Troncone, R.; Auricchio, S.; Rossi, M. Immunomodulatory effects of lactobacillus casei administration in a mouse model of gliadin-sensitive enteropathy. Scand. J. Immunol. 2011, 74, 335-341.

168. Sicherer, S.H.; Sampson, H.A. Food allergy. J. Allergy Clin. Immunol. 2010, 125, S116-S125.

169. Tsuda, M.; Hosono, A.; Yanagibashi, T.; Hachimura, S.; Hirayama, K.; Itoh, K.; Takahashi, K.; Kaminogawa, S. Prior stimulation of antigen-presenting cells with lactobacillus regulates excessive antigen-specific cytokine responses in vitro when compared with bacteroides. Cytotechnology 2007, 55, 89-101.

170. Kirjavainen, P.V.; Arvola, T.; Salminen, S.J.; Isolauri, E. Aberrant composition of gut microbiota of allergic infants: A target of bifidobacterial therapy at weaning? Gut 2002, 51, 51-55. 
171. Kuvaeva, I.B.; Orlova, N.G.; Veselova, O.L.; Kuznezova, G.G.; Borovik, T.E. Microecology of the gastrointestinal tract and the immunological status under food allergy. Nahrung 1984, 28, 689-693.

172. Francavilla, R.; Calasso, M.; Calace, L.; Siragusa, S.; Ndagijimana, M.; Vernocchi, P.; Brunetti, L.; Mancino, G.; Tedeschi, G.; Guerzoni, E.; et al. Effect of lactose on gut microbiota and metabolome of infants with cow's milk allergy. Pediatr. Allergy Immunol. 2012, 23, 420-427.

173. Del Giudice, M.M.; Leonardi, S.; Maiello, N.; Brunese, F.P. Food allergy and probiotics in childhood. J. Clin. Gastroenterol. 2010, 44, S22-S25.

(C) 2012 by the authors; licensee MDPI, Basel, Switzerland. This article is an open access article distributed under the terms and conditions of the Creative Commons Attribution license (http://creativecommons.org/licenses/by/3.0/). 